\title{
The impact of problem-based learning with argument mapping and online laboratory on scientific argumentation skill
}

\author{
Jumadi Jumadi $^{1}$, Riki Perdana ${ }^{2}$, Riwayani ${ }^{3}$, Dadan Rosana ${ }^{4}$ \\ ${ }^{1,3,4}$ Department of Physics Education, Universitas Negeri Yogyakarta, Indonesia \\ ${ }^{2}$ Faculty of Teaching Training and Education, Universitas Alma Ata, Indonesia
}

\begin{abstract}
Article Info
Article history:

Received Mar 17, 2020

Revised Nov 13, 2020

Accepted Jan 25, 2021

Keywords:

Argument mapping

Online laboratory

Problem-based learning

Scientific argumentation

ABSTRACT

Students in Indonesia still have the low level of scientific argumentation skills. This study purposed to examine the impact of Problem-based Learning (PBL) with Argument Mapping and Online Laboratory in improving the scientific argumentation skill. It describes the significance of the differences between participants who learn through PBL, PBL with Online Laboratory (PBL-OL), Problem-based Learning with Argument Mapping and Online Laboratory (PBL-AMOL) model. The population of this study were students from Madrasah Aliyah Negeri (MAN) Yogyakarta, Indonesia with a random sampling technique. This was quasi-experiment with pre and post test designs. In this study, there were 97 students at MAN 1 as respondent. Paired sample t-test, independent sample t-test and ANOVA mixed design was used to analysis data. The PBL-AMOL group has a significant difference based on pre-test and post-test (sig. 0000). The PBL-AMOL was most effective to improve the skill with gain score 0.43 (medium). Learning with the PBLAMOL model can be an alternative to solve the problems of creative thinking skill.
\end{abstract}

This is an open access article under the CC BY-SA license.

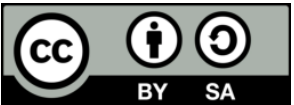

\section{Corresponding Author:}

Riki Perdana

Faculty of Teaching Training and Education

Universitas Alma Ata

Jl. Brawijaya No. 99, Yogyakarta, Indonesia

Email: rikiperdana@almaata.ac.id

\section{INTRODUCTION}

The Indonesian students' scientific argumentation skills are still low. The ability of scientific argumentation was only at level 1, only able to make claims [1]. In addition, they also cannot provide the correct concept to support claims [2]. Therefore, Indonesia needs learning model to improve these skills. One learning model that supports student activity is Problem-based Learning (PBL) model. According to Smith and Hung [3], in PBL students study the subject through pedagogical processes actively. Students also learn to be partners, are responsible for learning, work as a team, overcome new situations, and gain lifelong learning skills [4]. PBL is effective in improving student learning outcomes, reducing conceptual difficulties, and preventing the formation of alternative conceptions [5].

Another advantage of the PBL model is generating ideas and encouraging students to argue about certain problems being discussed [6]. The skills of students argue that accompanied by evidence is the center of scientific thought that helps in solving problems [7]. Scientific argumentation skills can help students engage in various scientific practices thereby increasing their knowledge of science content [8].

Efforts to improve students' scientific argumentation skills have been widely carried out by policy makers or school [9]. These efforts include: orienting students to problems and encouraging students to solve 
problems. This is in accordance with the PBL model because students will solve structured problems in small groups, and then present arguments to support their solutions [7]. In presenting arguments, students must be able to state based on the criteria and aspect of scientific argumentation skills. A complete argument consists of claims, data, warrant and rebuttal [10]. To achieve this aspect, students can be guided using the concept of mapping or argument mapping [11]. Argument mapping helps students to have a clear understanding of the topic or problem and the right attitude to solve the problem [12].

Students' argumentation skills can also be developed using online/internet based scientific argumentation learning [13]. Online learning can also strengthen student assessment and decision making because it enhances students' understanding of the social nature of the argument, critical thinking skills, and evidence-based reasoning [14]. The development of scientific argumentation skills using improved learning environment technology can really help students develop this 21 st century skills [15]. Online learning simulation (OLS) can improve students' understanding about knowledge content related to science topics [16]. It also allows students to feel the scientific reality that is impossible to do directly [17]. Online learning also can enhance learning motivation [18]. The simulation gives students the opportunity to interact more with learning topics because they can visualize complex and abstract scientific phenomena [19].

The aim of this study is to describe the significance of the differences between participants who learn through PBL-AMOL, OLS-PBL, PBL model and the effectiveness of these learning model in improving students' scientific argumentation skill. However, the PBL-AMOL model has never been aplied or previously applied to the teaching argumentation topic in class.

\section{RESEARCH METHOD}

\subsection{Model of research}

This study was quasi-experimental which is the objective was observing the scientific argumentation skill of students using PBL, PBL-OL, and PBL-AMOL. This PBL-AMOL model, however is the new learning and has not been apllied in imrpving scientific argumentation skill. The research design was pre-test and post control group design. The aim of the study was to know the students' scientific argumentation skill between the PBL-AMOL and PBL-OL as the experimental groups and PBL model as the control group. The first competency of all groups would be the same with the homogenity test of the variance from the pre-test data of each group.

According to Jager, et al. [20] confounding can be prevented by the use of randomization, restriction, or matching and be controlled by using stratification after completion of a study. In this study, the randomization and stratification was used to control confounding variable. The stratification started from Madrasah Aliyah Negeri (MAN) Yogyakarta City. There were three schools MAN 1, MAN 2 and MAN 3. Based on the the level of scientific argumentation or 21 st century skill, the sample choosed was MAN 1 because from perevious study [21], they had low level of scientific argumentation skill. In MAN 1 Yogyakarta, the class was chosed based on the material in the Indonesia Curriculum (K13). The material on this study was relevan with Grade XI science. There were four classess in XI Science MAN 1 Yogyakarta, but in this study only three class (97 students) as participant. The fourth class only consisted less than 20 students (special class). So, the total respondent only three science class from MAN 1 Yogyakarta Grade XI.

\subsection{Implementation}

There were 97 students from Madrasah Aliyah Negeri 1 Yogyakarta as the respondent. Random sampling technique was used from the Islamic State School in Yogyakarta, Indonesia. There are two classes for the online laboratory (OL) group. The first class was only taught with PBL-OL which consisted of 30 students. The second class was based on the PBL-AMOL learning model consisting of 30 students. The third class was only taught with the PBL model consisting of 30 students. All group were given six sessions, and each session consists of 60-90 minutes.

The research tools used are: 1) PBL-AMOL, PBL-OL, and PBL matrices that contain learning competencies based on topics, activities and assessments given to students during the learning process. All matrices have been validated by experts; 2) Guidelines for teachers which consist of lesson plans. This serves as a guide for teachers to convey the students with different approaches to each class; 3 ) Learning Materials which are modules developed by researchers; 4) Instruments to test the ability of scientific argumentation include open tests [21]. Assessment of student skills based on the rubric 0-5. Table 1 shows a description of each level. Students are asked to complete five questions, with each question containing aspects of the scientific arguments' skill. In this study, the aspect of scientific argumentation skill according to Riwayani [22] as shown in Table 2. 
Table 1 . Level of scientific argumentation skill

\begin{tabular}{cc}
\hline Level & Range \\
\hline Very low & $0-1.49$ \\
Low & $1.50-2.49$ \\
Average & $2.50-3.49$ \\
High & $3.50-4.49$ \\
Very high & $4.50-5.00$ \\
\hline
\end{tabular}

Table 2. Scientific argumentation skill

\begin{tabular}{cc}
\hline Aspect & Description \\
\hline Claim & Express a statement or opinion for solving the problem. \\
Data/Evidence & Explain data, evidence or facts that support the claim \\
Warrant & Analyzing the relationship between data and claims \\
Backing & Explain the basis of truth to support the claim \\
Rebuttal & Make the statements that conflict with claims, data, warrant, or backing \\
\hline
\end{tabular}

\subsection{Data collection and assessment}

Data were analyzed using SPSS 16 Software. The profiles of scientific argumentation skills were analyzed by descriptive statistics. Independent sample t test was used to determine differences of the results of the pre-test and post-test. In addition, the level of scientific argumentation skills of students will be analyzed based on the level claim, data, warrant, backing, and rebuttal. To find out the differences in each group based on the model taught, we use ANOVA mixed design analysis. The level of learning effectiveness in PBL-AMOL, PBL-OL, PBL only is calculated based on the value of the gain score with the Hake's formula [23]:

$$
\operatorname{Gain}(g)=\frac{\bar{x}_{\text {posttest }}-\bar{X}_{\text {pretest }}}{\text { maximum score }-\bar{X}_{\text {pretest }}}
$$

Where, $\mathrm{X}$ post-test is the average score of post-test and $\mathrm{X}$ pre-test is the average score of pre-test. The level of effectiveness is based on the above equation as $\mathrm{g} \geq 0.7$ high; $0.7>\mathrm{g} \geq 0.3$ medium; and $\mathrm{g}<0.3$ Low.

\section{RESULTS AND DISCUSSION}

According to Jones and Hafner [24] as one of the competencies in physics, students must be able to communicate based on written reports, presentations, and explanations directly. This skill is related to the scientific argumentation skills such as making claim, data, backing, warrant, and rebuttal. Argumentation skills allow students to explore, critics and wonder about scientific reality [25]. This activity is in accordance with physics, where students must be more critics [26]. Therefore, students' scientific argumentation skills need to be improved during the teaching of physics [27]. In this study, Paired sample t-test, independent sample t-test and ANOVA mixed design, and Homogenity test were used to analysis data. Table 3 shows the result of Homogenity test and for the other test will be described ont each group. Table 3 shows that sig value is $0.134>0.05$. It can be concluded that the initial skill or variance of students in the PBL, PBL-OL and PBLAMOL groups are the same or homogen.

Table 3. Test of homogeneity of variances

\begin{tabular}{cccc}
\hline Levene statistic & df1 & df2 & Sig. \\
\hline 2.057 & 2 & 194 & .134 \\
\hline
\end{tabular}

\subsection{PBL group}

Students were given questions based on five aspects of scientific argumentation. Table 4 shows the result of their skill in scientific argumentation. It shows that students' level in PBL Group are very low. The level of students in this group before and after learning is shown in Table 5. Paired sample t test is used to see whether there are significant differences in scientific argumentation skill as shown in Table 6. 
Table 4. Level of scientific argumentation skill of PBL-only group

\begin{tabular}{ccccccc}
\hline Aspect of scientific & \multicolumn{2}{c}{ Pre-test } & \multirow{2}{*}{ Description } & \multicolumn{2}{c}{ Post-test } & \multirow{2}{*}{ Description } \\
argumentation skill & Mean & SD & & SD & Low \\
\hline Claim & 0.38 & 1.34 & Very low & 2.03 & 2.15 & Low \\
Data & 0.19 & 0.61 & Very low & 1.78 & 2.00 & Very low \\
Warrant & 0.14 & 0.58 & Very low & 1.44 & 1.74 & Low \\
Backing & 0.08 & 0.45 & Very low & 1.61 & 2.00 & Very low \\
Rebuttal & 0.08 & 0.51 & Very low & 0.69 & 1.31 & Low \\
Overall & 0.17 & 0.37 & Very low & 1.51 & 0.33 &
\end{tabular}

Note: 4.50-5.00=very high; 3.50-4.49=high; $2.50-3.49=$ average; $1.50-2.49=$ low; $0-1.49=$ very low

Table 5. Level of students' scientific argumentation skills of PBL only group before and after learning

\begin{tabular}{|c|c|c|c|c|}
\hline \multirow{2}{*}{ Level } & \multicolumn{2}{|c|}{ Before } & \multicolumn{2}{|c|}{ After } \\
\hline & $\mathrm{f}$ & $\%$ & $\mathrm{f}$ & $\%$ \\
\hline Very high & 0 & 0 & 0 & 0 \\
\hline High & 0 & 0 & 0 & 0 \\
\hline Average & 0 & 0 & 0 & 0 \\
\hline Low & 0 & 0 & 17 & 53.13 \\
\hline Very low & 32 & 100 & 15 & 46.87 \\
\hline Overall & \multicolumn{2}{|c|}{ Mean $=0.15$ (Very low), SD=0.25 } & \multicolumn{2}{|c|}{ Mean $=1.28$ (Low), $\mathrm{SD}=0.63$} \\
\hline
\end{tabular}

Note: 4.50-5.00=very high; 3.50-4.49=high; $2.50-3.49=$ average; $1.50-2.49=$ low; $0-1.49=$ very low

Table 6. Paired sample t-test of the students' scientific argumentation skill of PBL only group

\begin{tabular}{cccccc}
\hline & Mean & SD & t-value & df & Sig \\
\hline Pre-test & 0.15 & 0.25 & \multirow{2}{*}{11.048} & \multirow{2}{*}{31} & 0.000 \\
Post-test & 1.28 & 0.63 & & & \\
\hline *significant at 0.05 & & & &
\end{tabular}

\subsection{PBL-OL group}

Students were given questions based on five aspects of scientific argumentation skills. Student answers are analyzed and the results are shown in Table 7. It shows that students in the PBL-OL group have very low level. The level of students' scientific argumentaion skills in PBL-OL Group before and after they were taught with this model is shown in Table 8. Paired sample t-test was used to determine differences in the results of scientific argumentation skills in this group as shown in Table 9.

Table 7. Level of scientific argumentation skill of PBL-OL group

\begin{tabular}{ccccccc}
\hline $\begin{array}{c}\text { Aspect of scientific } \\
\text { argumentation skill }\end{array}$ & \multicolumn{2}{c}{ Pre-test } & \multirow{2}{*}{ Description } & \multicolumn{2}{c}{ Post-test } & \multirow{2}{*}{ Description } \\
\hline Claim & 0.80 & 1.58 & Very low & 2.95 & 1.49 & Average \\
Data & 0.59 & 1.00 & Very low & 2.75 & 2.03 & Average \\
Warrant & 0.31 & 0.98 & Very low & 2.44 & 1.54 & Low \\
Backing & 0.39 & 0.97 & Very low & 2.78 & 1.85 & Average \\
Rebuttal & 0.09 & 0.40 & Very low & 1.88 & 1.34 & Low \\
Overall & 0.44 & 0.42 & Very low & 2.56 & 0.28 & Average \\
\hline Note: $4.50-5.00=$ very high; $3.50-4.49=$ high; $2.50-3.49=$ average; $1.50-2.49=l o w ; 0-1.49=$ very low &
\end{tabular}

Note: 4.50-5.00=very high; 3.50-4.49=high; $2.50-3.49=$ average; $1.50-2.49=$ low; $0-1.49=$ very low

Table 8. Level of students' scientific argumentation skills of PBL-OL group before and after learning process

\begin{tabular}{ccccc}
\hline Level & f & Before & f & After \\
\hline Very high & 0 & 0 & 0 & 0 \\
High & 0 & 0 & 0 & 0 \\
Average & 0 & 0 & 8 & 25 \\
Low & 1 & 3.12 & 23 & 71.88 \\
Very low & 31 & 96.88 & 1 & 3.12 \\
Overall & Mean=0.37 (Very low), SD=0.35 & Mean=2.19 (Low), SD $=0.53$ \\
\hline
\end{tabular}

Note: 4.50-5.00=very high"; 3.50-4.49=high; 2.50-3.49=average; 1.50-2.49=low; 0-1.49=very low

Table 9. Paired sample t-test of the students' scientific argumentation skill of PBL-OL group

\begin{tabular}{cccccc}
\hline & Mean & SD & t-value & df & Sig \\
\hline Pre-test & 0.37 & 0.35 & -18.010 & \multirow{2}{*}{31} & $0.000 *$ \\
Post-test & 2.19 & 0.53 & & & \\
\hline *significant at 0.05 & & & & &
\end{tabular}




\subsection{PBL-AMOL group}

Students were given questions based on five aspects of scientific argumentation skills. Student answers are analyzed and the results are shown in Table 10. The quality of scientific argumentation that are still very low in the PBL-AMOL group. It shows that their skills related to scientific argumentation have not been improved. The level of students' scientific argumentation skills in PBL-AMOL Group before and after they were taught with this model is shown in Table 11. Paired sample t-test was used to determine differences in the results of scientific argumentation skills in this group as shown in Table 12.

Table 10. Level of scientific argumentation skill of PBL-AMOL group

\begin{tabular}{ccccccc}
\hline Aspect of scientific & \multicolumn{2}{c}{ Pre-test } & \multirow{2}{*}{ Description } & \multicolumn{2}{c}{ Post-test } & \multirow{2}{*}{ Description } \\
argumentation skill & Mean & SD & & SD & Average \\
\hline Claim & 1.79 & 2.09 & Very low & 3.30 & 1.73 & High \\
Data & 0.83 & 0.89 & Very low & 4.05 & 3.22 & Average \\
Warrant & 0.79 & 1.23 & Very low & 2.74 & 1.70 & High \\
Backing & 0.74 & 1.28 & Very low & 3.98 & 2.28 & Low \\
Rebuttal & 0.18 & 0.74 & Very low & 2.42 & 1.39 & Average \\
Overall & 0.87 & 0.58 & Very low & 3.30 & 0.28 &
\end{tabular}

Note: $4.50-5.00=$ very high; $3.50-4.49=$ high; $2.50-3.49=$ average; $1.50-2.49=$ low; $0-1.49=$ =ery low

Table 11. Level of students' scientific argumentation skills of PBL-AMOL group before and after learning

\begin{tabular}{|c|c|c|c|c|}
\hline \multirow{2}{*}{ Level } & \multicolumn{2}{|c|}{ Before } & \multicolumn{2}{|c|}{ After } \\
\hline & $\mathrm{f}$ & $\%$ & $\mathrm{f}$ & $\%$ \\
\hline Very high & 0 & 0 & 0 & 0 \\
\hline High & 0 & 0 & 3 & 9.09 \\
\hline Average & 0 & 0 & 22 & 66.67 \\
\hline Low & 1 & 3.03 & 7 & 21.21 \\
\hline Very low & 32 & 96.97 & 1 & 3.03 \\
\hline Overall & \multicolumn{2}{|c|}{ Mean $=0.76$ (Very low), $\mathrm{SD}=0.36$} & \multicolumn{2}{|c|}{ Mean $=2.76$ (Average), $\mathrm{SD}=0.66$} \\
\hline
\end{tabular}

Note: $4.50-5.00=$ very high; 3.50-4.49=high; $2.50-3.49=$ average; $1.50-2.49=$ low; $0-1.49=$ very low

Table 12. Paired sample t-test of the students' scientific argumentation skill of PBL-AMOL group

\begin{tabular}{cccccc}
\hline & Mean & SD & t-value & df & Sig \\
\hline Pre-test & 0.76 & 0.35 & \multirow{2}{*}{-16.384} & 32 & \multirow{2}{*}{$0.000^{*}$} \\
Post-test & 2.76 & 0.66 & & &
\end{tabular}

\subsection{Comparison of all group}

In this study, we use ANOVA mixed design to determine the greatest influence between PBL, PBLOL, and PBL-AMOL learning on students' scientific argumentation skills. The results as shown in Table 13. A comparison of all groups was also analyzed using the gain score. The results are presented in Table 14. It shows that there is an increase in all groups. But, the level of effectiveness of all groups is still low.

Table 13. Result of ANOVA mixed design analysis

\begin{tabular}{ccc}
\hline Group & Sig. & Partial Eta Squared \\
\hline PBL only & 0.000 & 0.529 \\
PBL with online laboratory & 0.000 & 0.745 \\
PBL with argument mapping-online laboratory & 0.000 & 0.785 \\
\hline
\end{tabular}

Table 14. Gain score of all group

\begin{tabular}{ccccc}
\hline Group & Average of pre-test & Average of post-test & Gain Score & Description \\
\hline PBL-only & 0.15 & 1.28 & 0.23 & Low \\
PBL-OL & 0.37 & 2.19 & 0.39 & Medium \\
PBL-AMOL & 0.76 & 2.76 & 0.47 & Medium \\
\hline Note: $\mathrm{g}>0.70=$ high; $0.3<\mathrm{g}<0.7=$ =medium; $\mathrm{g}<0.3=$ low & &
\end{tabular}




\subsection{DISCUSSION}

The mean of scientific argumentation skills of students in PBL group was very low before learning process (mean 0.17, $\mathrm{SD}=0.37$ ). Among the 25 questions, the lowest student answers are in aspect rebuttal with mean 0.08 (very low). Meanwhile, the highest average score of student answer is aspect claim 0.38 (very low) and the backing and rebuttal aspects showed the lowest average of 0.08 (very low). In general, the average scientific argumentation skills of students in the PBL only based on the pre-test were 0.17 (very low).

After students are taught with PBL learning, there is an increasing in several aspects. Claims, data and backing aspects increased from "very low" to "low" level. Meanwhile, the aspects of warrant and rebuttal are still at a "very low" level. The highest average is aspect of claim (2.03) while the aspect of rebuttal shows the lowest (0.69). The students from the PBL group had very low scientific argumentation skills (mean $=0.15$, $\mathrm{SD}=0.25)$ based on pre-test and all students $(\mathrm{N}=32)$ had a "very low" level. After students are taught with PBL model, the number of students at "low" level increases $(53.13 \%)$ and students at the "very low" level decreases $(46.87 \%)$. Despite the increase, the level of scientific argumentation skills of this group is still at a low level (1.28; $\mathrm{SD}=0.63)$. It shows that the model was used in teaching has no significant effect in improving the skills.

The results of scientific argumentation skills in PBL group after learning process show a significant difference. The difference in the mean of post-test (1.50) and the pre-test (0.17) was 1.33 . It indicates that PBL model helped in increasing the level of students' scientific argumentation skills. This is similar with Nurinda, et al. [28], problem-based learning can be used to improve students' scientific argumentation skills. According to Ponimin, et al. [29], the scientific argumentation skill in the experimental class (using the PBL model) were better than the control class (non-PBL). Because PBL can help students generate ideas and encourage debate or discussion about certain problems [6].

For PBL-OL group, the students' answers on the claim aspect showed the highest mean (0.80: very low) and the rebuttal aspects showed the lowest (0.09: very low) based on pre-test. In general, the students' scientific argumentation skills in the PBL-OL group based on the pre-test were 0.44 (very low). After students are taught with PBL-OL, all aspect of scientific argumentation skills is increase. Claims, data and backing aspects from "very low" increased to "average" level. Meanwhile, the aspects of warrant and rebuttal are still at "low" level. The highest mean is aspect of claim (2.95) while the aspect of rebuttal shows the lowest (1.88).

The level of students in the PBL-OL group before learning process was at very low (96.88\%) and only 1 student $(3.12 \%)$ showed a low level. In general, the students in this group have a very low level of with mean 0.37 with $\mathrm{SD}=0.35$. No one shows a high level of scientific argumentation skills. After students are taught with PBL-OL, the number of students at the "low" level (71.88\%) and average level $(25 \%)$ increases, and students at the "very low" level decreases (3.12\%). Despite the increase, overall, the students' level of this group is still at low level $(2.19 ; \mathrm{SD}=0.53)$. It shows that the model was used in teaching has no significant effect in increasing the level of students. The results of scientific argumentation skills in PBL-OL group after learning process show a significant difference. The difference in the mean post-test (2.19) and the pre-test (0.37) was 1.82 indicating that PBL-OL significantly helped in increasing the level of students' scientific argumentation skills.

For PBL-AMOL Group, the students' answers on the claim aspect showed the highest (1.79; very low) and the rebuttal aspects showed the lowest (0.18; very low). In general, the students' level in the PBLAMOL group based on the pre-test were 0.87 (very low). After students are taught with PBL-AMOL model, all aspect of scientific argumentation skills is increase. Claims and warrant were initially at "very low" increased to "average". Aspect data and backing increase to "high" level. Meanwhile, the rebuttal is still at "low" level. This is similar to Nurinda, et al. [30], where PBL was able to increase $27.27 \%$ of students' rebuttal abilities. The highest mean is aspect data (4.05) while the aspect of rebuttal shows the lowest (2.42).

The level of students in the PBL-AMOL group before learning process was very low level $(96.97 \%)$ and only 1 students $(3.03 \%)$ showed a low level. In general, the results of the pre-test this group have a very low level (0.76; $\mathrm{SD}=0.36)$. There is no students shows a high level of scientific argumentation skills. After students are taught using PBL-AMOL model, there is an increasing the level of student's skill at "low" level (21.21\%), average level (66.67\%), high level (9.09) and students at the "very low" level decreases (3.03\%). Despite the increase, overall, the level of scientific argumentation skills of the PBL-AMOL group is still at average level $(2.76 ; \mathrm{SD}=0.66)$. It shows that the model was used in teaching has effect in increasing the level of students' scientific argumentation skills. The results of scientific argumentation skills in PBL-AMOL group after learning process show a significant difference. The difference in the mean of post-test (2.76) and the pre-test (0.76) was 2.00 indicating that PBL-AMOL significantly helped in increasing the level of students. 
The Partial Eta Squared value of PBL is 0.529 , PBL-OL is 0.745 and PBL-AMOL is 0.785 . According to Riwayani [22], the meaning of this value: PBL only is able to improve students' scientific argumentation skills by $52.9 \%$, PBL-OL $74.5 \%$ and PBL-AMOL 78.5\%. These results indicate that the PBLAMOL learning is be most effective in improving students' scientific argumentation skills. It similiar according to Perdana, et al. [31], where the integrated of PBL-OL and concept maps give the positive impact on students' achievement and 21 st skills. In the PBL-AMOL group there is an explanation of scientific argumentation theory that students must understand [13]. In addition, mapping arguments help students in solving problems and facilitate students to have a clear understanding [12].

Based on the gain score, there is an increasing of scientific argumentation skill in all groups also as shown in Figure 1. The PBL group is at low level. This is because students are not directed how to make the correct scientific arguments. They are only encouraged to solve problems, without being guided by the criteria for good scientific argumentation skills. The PBL-OL group is at the middle level. It is because students can looking for the information on several websites. They become more skilled in determining how to properly claim. The PBL-AMOL group is also at the middle level but is better than the two existing groups, because student was guided to provide good scientific arguments through concept maps and compared with several aspects of scientific argumentation on several websites.

Estimated Marginal Means of MEASURE_1

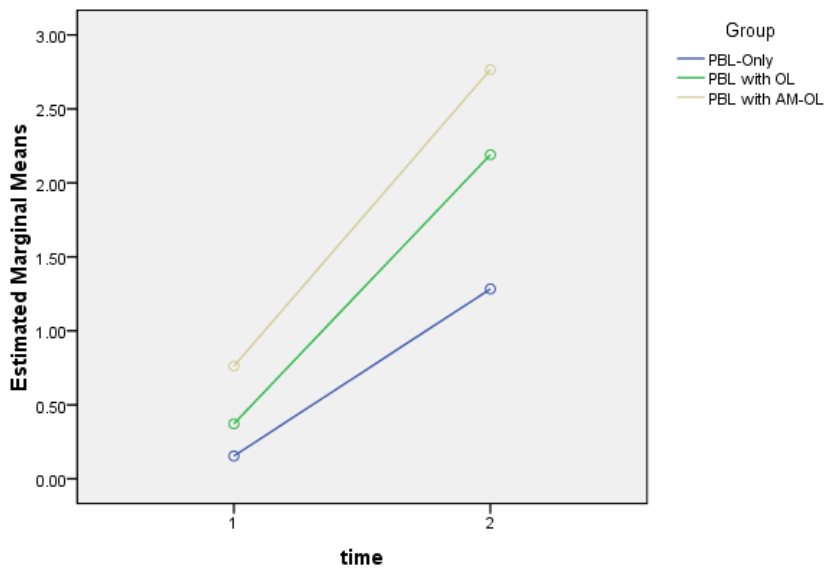

Figure 1. Pre-test and post-test all group

\section{CONCLUSION}

The result of data analysis showed that the PBL-AMOL model was more effective in improving student's scientific argumentation skills than the PBL-OL and PBL model. Based on test, the PBL-AMOL is able to stimulate students in claim, data, warrant, backing, and rebuttal skill in scientific argumentation skill. The PBL-AMOL model can be regarded as the solution to solve the problems of students' scientific argumentation skill. Hence, the final results indicate that there is a significant difference (sig .000) between the PBL-AMOL, PBL-OL, and PBL groups. In addition, the PBL-AMOL model had also proven to be effective for teaching scientific argumentation skill which shows a significant difference (sig .000) between the pre-test and post-test.

\section{REFERENCES}

[1] A. D. Wardani, et al., "The ability of scientific argumentation and physics problem solving of high school students on Force and Work subject matter," in Pros. Semnas Pendidikan IPA Pascasarjana UM, 2016, vol. 1, pp. 13-28.

[2] T. N. Ain, H. A. C. Wibowo, A. Rohman, and U. A. Deta, "The scientific argumentation profile of physics teacher candidate in Surabaya," in Journal of Physics: Conference Series, vol. 997, 2018, doi: https://doi.org/10.1088/1742-6596/997/1/012025.

[3] C. S. Smith and L. C. Hung, "Using problem-based learning to increase computer self-efficacy in Taiwanese students," Interact. Learn. Environ, vol. 25, no. 3, pp. 329-342, 2017, doi: 10.1080/10494820.2015.1127818.

[4] A. Alrahlah, "How effective the problem-based learning (PBL) in dental education. A critical review," Saudi Dental Journal, vol. 28, no. 4, pp. 155-161, 2016, doi: https://doi.org/10.1016/j.sdentj.2016.08.003. 
[5] Y. Ayyildiz and L. Tarhan, "Problem-based learning in teaching chemistry: enthalpy changes in systems," Res. Sci. Technol. Educ, vol. 36, no. 1, pp. 35-54, 2018, doi: 10.1080/02635143.2017.1366898.

[6] N. S. Ismail, J. Harun, M. A. Z. M. Zakaria, and S. M. Salleh, "The effect of Mobile problem-based learning application DicScience PBL on students' critical thinking," Think. Ski. Creat., vol. 28, pp. 177-195, 2018, doi: https://doi.org/10.1016/j.tsc.2018.04.002.

[7] B. R. Belland, K. D. Glazewski, and J. C. Richardson, "Problem-based learning and argumentation: Testing a scaffolding framework to support middle school students' creation of evidence-based arguments," Instr. Sci., vol. 39, pp. 667-694, 2011, doi: https://doi.org/10.1007/s11251-010-9148-z.

[8] J. Grooms, P. Enderle, and V. Sampson, "Coordinating scientific argumentation and the next generation science standards through argument driven inquiry," Sci. Educ, vol. 24, no. 1, pp. 45-50, 2015.

[9] J. B. Henderson, K. L. McNeill, M. González-Howard, K. Close, and M. Evans, "Key challenges and future directions for educational research on scientific argumentation," J. Res. Sci. Teach., vol. 55, pp. 5-18, 2018, doi: https://doi.org/10.1002/tea.21412.

[10] C. Martín-Gámez and S. Erduran, "Understanding argumentation about socio-scientific issues on energy: a quantitative study with primary pre-service teachers in Spain," Res. Sci. Technol. Educ, vol. 36, no. 4, pp. 463-483, 2018, doi: 10.1080/02635143.2018.1427568

[11] M. Metcalfe and S. Sastrowardoyo, "Complex project conceptualisation and argument mapping," Int. J. Proj. Manag, vol. 31, no. 8, pp. 1129-1138, 2013, doi: https://doi.org/10.1016/j.ijproman.2013.01.004.

[12] M. Davies, "Concept mapping, mind mapping and argument mapping: What are the differences and do they matter?" High. Educ, vol. 62, pp. 279-301, 2011, doi: https://doi.org/10.1007/s10734-010-9387-6.

[13] K. H. Yeh and H. C. She, "On-line synchronous scientific argumentation learning: Nurturing students' argumentation ability and conceptual change in science context," Comput. Educ., vol. 55, no. 2, pp. 586-602, 2010, doi: https://doi.org/10.1016/j.compedu.2010.02.020.

[14] C. Y. Tsai, "The effect of online argumentation of socio-scientific issues on students' scientific competencies and sustainability attitudes," Comput. Educ, vol. 116, pp. 14-27, 2018, doi: 10.1016/j.compedu.2017.08.009.

[15] D. Clark, et al., "Scaffolding scientific argumentation between multiple students in online learning environments to support the development of 21 st century skills," in the National Academies' Board on Science Education workshop on Exploring the Intersection of Science Education and 21 st Century Skills, 2009, pp. 1-44.

[16] R. Lamb, "Examination of allostasis and online laboratory simulations in a middle school science classroom," Comput. Human Behav., vol. 39, pp. 224-234, 2014, doi: https://doi.org/10.1016/j.chb.2014.07.017.

[17] R. L. Lamb, "Examination of the Effects of Dimensionality on Cognitive Processing in Science: A Computational Modeling Experiment Comparing Online Laboratory Simulations and Serious Educational Games," J. Sci. Educ. Technol, vol. 25, pp. 1-15, 2016.

[18] R. Perdana, A. Wahyu, and H. Kuswanto, "Simulation using VBA in Microsoft Excel to Enhance Pre-service Physics Teachers' Motivation,” Int. J. Sci. Bus., vol. 3, no. 3, pp. 114-123, 2019.

[19] J. Shen, S. Jiang, and O. L. Liu, "Reconceptualizing a College Science Learning Experience in the New Digital Era: A Review of Literature," in Ge X., Ifenthaler D., Spector J. (eds). Emerging Technologies for STEAM Education. Educational Communications and Technology: Issues and Innovations. Springer, Cham, 2015.

[20] K. J. Jager, C. Zoccali, A. Macleod, and F. W. Dekker, "Confounding: what it is and how to deal with it," Kidney Int., vol. 73, no. 3, pp. 256-260, 2008.

[21] R. Perdana, R. Riwayani, J. Jumadi, and D. Rosana, "Modification Level and Test of Scientific Argumentation Skill: Development and Validity," International Journal of Evaluation in Research and Education (IJERE), vol. 9, no. 3, pp. 769-777, 2020.

[22] Riwayani, "Development of PBL Model Physics Learning Media with OLS-assisted Argument Mapping to Improve the Ability of Scientific Argument and Digital Literacy of High School Students (in Bahasa)," Master Thesis, Universitas Negeri Yogyakarta, 2019. [Online]. Available: http://eprints.uny.ac.id/65851/

[23] R. R. Hake, R. Wakeland, A. Bhattacharyya, and R. Sirochman, "Assessment of individual student performance in an introductory mechanics course," AAPT Announc., vol. 24, no. 4, p. 76, 1994.

[24] R. H. Jones and C. A. Hafner, Understanding digital literacies: A practical introduction. Routledge, 2012.

[25] N. M. Mirza and A. N. Perret-Clermont, Argumentation and education: Theoretical foundations and practices. Springer US, 2009.

[26] E. Etkina and G. Planinšič, "Defining and Developing 'Critical Thinking' Through Devising and Testing Multiple Explanations of the Same Phenomenon," Phys. Teach, vol. 53, no. 7, pp. 432-437, 2015.

[27] J. Wang, "Scrutinising the positions of students and teacher engaged in argumentation in a high school physics classroom," Int. J. Sci. Educ., vol. 42, no. 1, pp. 25-49, 2020, doi: 10.1080/09500693.2019.1700315.

[28] S. Nurinda, S. Sajidan, and B. A. Prayitno, "Effectiveness of problem-based learning module as an instructional tool in improving scientific argumentation skill," Biosaintifika J. Biol. Biol. Educ, vol. 10, no 2, pp. 334-340, 2018.

[29] Ponimin, et al., "The effect of problem-based learning using circle share activity on argumentation ability: A case study on uniform circular motion," in AIP Conference Proceedings, 2018, doi: https://doi.org/10.1063/1.5054499.

[30] S. Nurinda, S. Sajidan, and B. A. Prayitno, "Enhancing High School Students's Rebuttals as An Important Aspect of Scientific Argumentation Skill Through Problem Based Learning," Proc. 1st Annual Int Conf on Mathematics, Science, and Education (ICoMSE 2017), 2018, doi: https://doi.org/10.2991/icomse-17.2018.35.

[31] R. Perdana, et al., "The online laboratory simulation with concept mapping and problem based learning (OLSCMPBL): Is it effective in improving students' digital literacy skills?” J. Cakrawala Pendidik., vol. 39, no. 2, pp. 382-394, 2020. 